\title{
High high-density-lipoprotein cholesterol in African children and adults in a population free of coronary heart disease
}

\author{
A R P WALKER, B FAITH WALKER
}

British Medical fournal, 1978, 2, 1336-1338

\section{Summary and conclusions}

The serum concentration of high-density lipoprotein cholesterol and the proportion it constitutes of total serum cholesterol are high in children and low in sufferers from coronary heart disease (CHD). Studies in elderly black Africans in Western Transvaal showed them to be free of CHD. HDL concentrations measured at birth and in groups of 10- to 12-year-olds, 16- to 18-year olds, and 60- to 69-year-olds showed mean values of $0.96,1.71$, 1.58 , and $1.94 \mathrm{mmol} / \mathrm{l}(36,66,61$, and $65 \mathrm{mg} / 100 \mathrm{ml})$ respectively; these concentrations constituted about $56 \%, 54 \%$, and $45 \%$, and $47 \%$, of total cholesterol. Values thus did not fall from youth to age as they did in whites.

Rural South African blacks live on a diet high in fibre and low in animal protein and fat; children are active; and adults remain active even when old. These high values of HDL may well be representative for a population that is active, used to a frugal traditional diet, and free from CHD.

\section{Introduction}

Concentration of serum high-density lipoprotein (HDL) or $\alpha$-lipoprotein cholesterol seems to be highest at birth and lowest in patients with coronary heart disease (CHD). The fraction that HDL cholesterol constitutes of total serum cholesterol is also high before puberty and lowest in patients with CHD. ${ }^{1}$ ?

Because of interest in the relationship between HDL cholesterol and CHD we examined HDL cholesterol concentrations in groups of rural black South Africans. In the village studied elderly blacks were free of CHD; the villagers' diet was low in energy and animal protein and fat intakes and high in crude fibre intake; and both young and old were physically active. We thus had an opportunity to study serum HDL cholesterol concentrations in a population with few risk factors for CHD and several protective factors.

\section{Subjects and methods}

Studies were made in western Transvaal, at a Tswana village about 100 miles from Johannesburg. We examined four age groups.

Infants-Sera from cord blood were obtained at the local mission hospital from consecutive births of 15 boys and 15 girls.

Children-Forty boys and 40 girls aged 10-12, all of whom were healthy, were studied. Most had normal weight for height, but over half had weight for age below the 3rd percentile of Harvard reference standards. ${ }^{3}$ Surveys at many schools indicated normal serum albumin values and excellent school attendance records. ${ }^{4}$ Apart from walking to school, often over 4 to 8 miles ( 6 to $13 \mathrm{~km}$ ), rural black pupils were very active at play, and performed well at races. ${ }^{56}$

MRC Human Biochemistry Research Unit, South African Institute

for Medical Research, Johannesburg, South Africa

A R P WALKER, DSC, head of unit

B F WALKER, technician
Adolescents-Of the 50 boys and 50 girls aged 16-18, seven boys and three girls had weight for age below the 3rd percentile, while 11 girls showed the obesity common in adolescent African girls (triceps skinfold thickness $.25 \mathrm{~mm}^{7}$ ). The boys were more active than the girls.

Adults-In the village 98 men and 184 women were aged 60-69 years. Many men were away working in the towns. Ninety-three men and 168 women were examined, all of them in good health. The remainder were either unwell, away, or unwilling to participate. We obtained 12-lead ECG tracings ${ }^{8}$ using a Kawasaki $800-\mathrm{W}$ generator and two Sandborn Viso-Cardiette machines and found no evidence of ischaemic heart disease using World Health Organisation criteria." Details of results will be given eisewhere. No case of CHD has yet been admitted to the local hospital. Our observations were the same as those obtained in analogous studies on elderly blacks in other villages. ${ }^{10}$ Absence of CHD was entirely expected, since it is uncommon even in urban populations despite the presence of all risk factors to a significant extent. ${ }^{11} 12$ Seven elderly men but no women smoked regular v. Eleven men and 27 women had a diastolic pressure of $90 \mathrm{~mm}$ Ig or more.

DIET

The diet was basea primarily on cereals, principally maize, with legumes, vegetables, fruit, and wild greens. ${ }^{4}$ Appreciable amounts of meat and milk were consumed only irregularly. In the children, adolescents, and adults mean daily energy intakes, from 24-hour recall data, were about $6.7,8.4$, and $8.8 \mathrm{MJ}(1600,2000$, and 2100 kcal) respectively; on average $10^{\circ}{ }^{\circ}$, was derived from protein (a quarter was of animal origin), $13^{\circ}$, from fat (a third of animal origin), $75^{\circ}$ o from carbohydrate $\left(15^{\circ}\right.$ " from sucrose). Daily crude fibre intakes averaged roughly $7 \mathrm{~g}$ and $12 \mathrm{~g}$ in the groups of pupils and $15 \mathrm{~g}$ in adults.

METHOD

A 15-ml sample of blood was taken from pupils (after written permission had been granted by parents or guardians) and adults after an overnight fast. The blood samples were centrifuged within an hour of collection, the serum separated off, kept cool in vacuum flasks, and temporarily stored in the local hotel's refrigerator. Samples were transported to Johannesburg in flasks and stored at $-20 \mathrm{C}$. Analysis, in duplicate, was completed within two weeks. HDL cholesterol was determined by adding heparin and manganese chloride solutions to the serum, allowing precipitate to form, centrifuging at $6000 \mathrm{rpm}$, and estimating cholesterol concentration in the supernatant liquid. ${ }^{13}$ For this procedure and for estimating total serum cholesterol concentration a commercial kit (Boehringer, Mannheim, catalogue number 231347 (CHOD-PAP)) was used, with Preciset cholesterol (Boehringer, Mannheim, catalogue number 125512) as a standard and Precilip (Boehringer, Mannheim, catalogue number 125059) for quality control. In duplicate analysis of 20 samples for HDL cholesterol and total cholesterol coefficients of variation were $3 \cdot 8^{\circ}$ ind $3 \cdot 3 \%$ respectively.

\section{Results and comment}

Results are shown in the table and compared with values measured by the same method in white populations. ${ }^{21419}$

Infants-Values for cord blood (which, for serum cholesterol concentrations, were virtually the same as those found in urban infants ${ }^{21}$ ) were closely similar to those reported for black and white babies in the USA. ${ }^{14}$

Children-Data on black and white children aged 5-16 years in 
Mean serum HDL cholesterol concentration $( \pm S D)$ and its proportion of total cholesterol in African and other populations

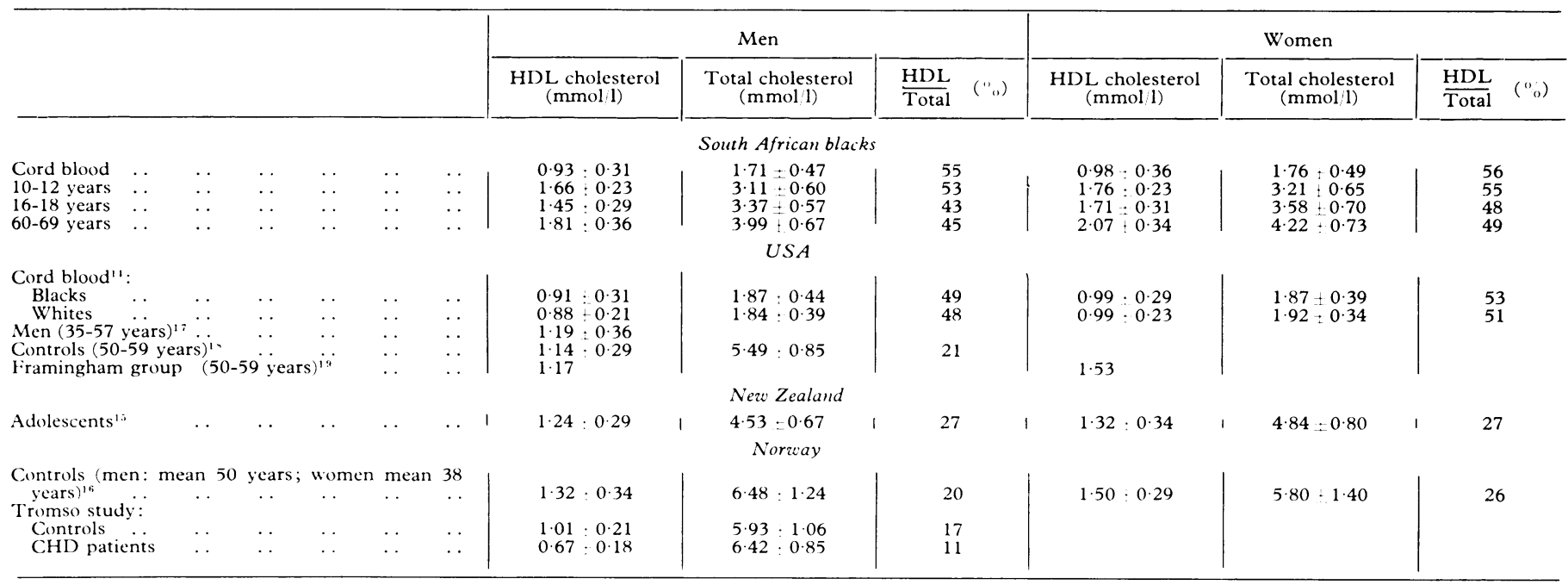

Conversion: SI to traditionsl units-Cholesterol: $1 \mathrm{mmol} 1=38.6 \mathrm{mg} 100 \mathrm{ml}$.

New Orleans' suggested that values for HDL cholesterol possibly were at their highest at this prepuberty age.

Adolescents-By 16-18 years mean HDL cholesterol concentrations for boys, but not girls, had fallen significantly $(P<0.01)$. Yet the fall was much greater in New Zealand adolescents and was associated with a much greater rise in total serum cholesterol concentration with age. ${ }^{16}$

Adults-HDL cholesterol concentration and its proportion of total cholesterol were significantly higher $(\mathrm{P}<0.01$ and $\mathrm{P}<0.05$, respectively) than those in youth. Our data agreed with those in Nigerian men,"I among whom the mean proportion for $x$-lipoprotein determined electrophoretically was 44" ${ }^{\prime}$. High concentrations have also been reported in adult Eskimos." In middle-aged and elderly whites, in strong contrast, mean values for HDL cholesterol were much lower than in adolescence, the considerable fall in the proportion of HDL cholesterol concentration being linked with the considerable rise with age of serum cholesterol concentration. Interestingly, a study of active skiers in Oslo showed a rise in HDL cholesterol concentration from adolescence to old age..$^{16}$

Other observations-Higher values in women than men, conspicuous in whites, ${ }^{1,1618}$ also prevailed in blacks.

\section{Discussion}

In so far as HDL cholesterol concentration and its proportion of total cholesterol is a measure of the atherosclerotic process and susceptibility to $\mathrm{CHD}$, our findings suggest that blacks are less susceptible than whites: elderly blacks are "younger" in vascular age than white adolescents. Studies of the chemical composition of aorta from blacks and whites confirm this suggestion. ${ }^{23}$ These findings lend additional force to the repeated recommendation that preventive action against CHD should begin early in youth.

But how protective or predictive is the HDL cholesterol concentration ? Norwegian skiers ${ }^{16}$ and American runners ${ }^{17}$ had values as high as those of African boys $(1.66 \mathrm{mmol} / 1(64 \mathrm{mg}$ $100 \mathrm{ml})$ ), but, although these groups are less at risk than most Westerners, they are still relatively prone to CHD. Young American vegetarians consuming a macrobiotic diet had a mean HDL cholesterol value lower than that of controls $(1.09 \mathrm{mmol} / 1$ (42 mg/100 ml) compared with $1.27 \mathrm{mmol} / 1(49 \mathrm{mg} / 100 \mathrm{ml})$ ), but they also had a far lower total cholesterol value $(3.26 \mathrm{mmol} / \mathrm{l}$ $(126 \mathrm{mg} / 100 \mathrm{ml})$ compared with $4.77 \mathrm{mmol} / 1(184 \mathrm{mg} / 100 \mathrm{ml}))^{2.4}$ The protective effect of a high HDL cholesterol concentration may depend partially on a low total serum cholesterol concentration or, perhaps more appositely, on a low concentration of low-density-lipoprotein cholesterol.

A priority in future studies is to improve accuracy of measurement of HDL cholesterol level; at present, the technical error is about $0.13 \mathrm{mmol} / 1(5 \mathrm{mg} / 100 \mathrm{ml}) .^{1 \times}$ Epidemiologically we need to know what effects changes in diets may have on HDL concentrations, ${ }^{2.5}$ the effect of different levels of physical activity (at work and at leisure ${ }^{26}$ ), and more about HDL concentrations in populations with different degrees of susceptibility. For example, adult populations in London, where the incidence of CHD in whites is 10 times that in immigrants from the Caribbean and even higher in Asian immigrants than in whites, ${ }^{27}$ deserve study. Nevertheless, the finding of similar HDL concentrations in Norwegian, Finnish, and Lapp men but a lower incidence of CHD among the Lapps cautions against excessive euphoria over the relationship between HDL and CHD. $\because *$

\section{References}

${ }^{1}$ Srinvasan, S R, Frerichs, R R, and Berenson, G S, Clinica Chimica Acta, 1975, 60, 293.

2 Miller, N E, et al, Lancet, 1977, 1, 965.

3 Walker, A R P, and Walker, B F, South African Medical fournal, 1977, 51, 707

4 Walker, A R P, et al, Fournal of Tropical Medicine and Hygiene, 1978, 81, 2.

${ }^{5}$ Botha, J F, Clark, D, and Jokl, E, South African Medical fournal, 1945, 19, 381.

6 Walker, A R P, et al, Tropical and Geographical Medicine, 1972, 24, 347.

'Walker, A R P, and Walker, B F, Fournal of Tropical Medicine and Hygiene, $1977,50,119$.

${ }^{8}$ Walker, A R P, and Walker, B F, American Heart fournal, 1969, 77, 441.

${ }^{9}$ World Health Organisation, First Report of the Expert Committee on Cardiovascular Diseases and Hypertension: Hypertension and Coronary Heart Disease. Geneva, WHO, 1959.

1" Walker, A R P, American Heart fournal, 1975, 89, 133.

11 Walker, A R P, and Walker, B F, Tropical and Geographical Medicine, $1978,30,91$.

12. Walker, A R P, and Isaacson, C, British Medical fournal, 1977, 1, 1660

${ }^{13}$ Burstein, M, and Samaille, J, Clinica Chimica Acta, 1960, 5, 609.

14 Glueck, C J, et al, Metabolism, 1977, 26, 347.

15 Stanhope, J M, Sampson, V M, and Clarkson, P M, Lancet, 1977, 1, 968

${ }^{16}$ Enger, S C, et al, Scandinavian fournal of Clinical and Laboratory Investigation, 1977, 37, 251 .

${ }^{17}$ Hulley, S B, Cohen, R, and Widdowson, G, fournal of the American Medical Association, 1977, 238, 2269.

18 Wood, P D, et al, Metabolism, 1976, 25, 1249

${ }^{19}$ Gordon, T, et al, American fournal of Medicine, 1977, 62, 707.

${ }^{20}$ Bersohn, I, and Wayburne, S, American fournal of Clinical Nutrition, $1956,4,117$.

${ }^{21}$ Onitiri, A C, Sander, M, and Boyo, A E, Clinica Chimica Acta, 1977, 81, 57.

22. Bang, $\mathrm{H} \mathrm{O}$, and Dverberg, J, Acta Medica Scandinavica, 1972, 192, 85.

23 Anderson, M, et al, Archives of Pathology, 1959, 68, 380.

${ }^{24}$ Sacks, F M, et al, New England Fournal of Medicine, 1975, 292, 1148.

${ }_{25}$ Durrington, P N, et al, Atherosclerosis, 1977, 27, 465.

$2{ }^{2}$ Hickey, N, et al, British Medical fournal, 1975, 3, 507.

27 Clayton, D, et al, Lancet, 1975, 2, 833.

28 Forde, O H, et al, Acta Medica Scandinavica, 1978, 203, 21.

(Accepted 11 September 1978) 